\title{
Marmara Denizi, Bandırma Körfezi sarıkuyruk istavrit [(Trachurus mediterraneus (Steindachner, 1868)]' in bazı populasyon parametreleri
}

\author{
Hatice TORCU KOÇ*, Zeliha ERDOĞAN \\ Balikesir Üniversitesi, Fen-Edebiyat Fakültesi, Biyoloji Bölümü, Çağış Yerleşkesi, Balıkesir, Türkiye \\ Geliș Tarihi (Recived Date): 03.04.2018 \\ Kabul Tarihi (Accepted Date): 11.10.2018
}

\section{Özet:}

Bu çalışmada, Eylül 2013-Aralık 2015 yılları arasında Marmara Denizi balıkçılı̆̆ında ekonomik yönden önemli olan sarıkuyruk istavrit populasyonunun boy ve ağırlık frekansları, boy-ağırlık iliş̧kisi, yaş ve eşey dağılımları, Von Bertalanffy büyüme eşitliği, kondisyon faktörü, gonadosomatik indeks, mortalite gibi bazı biyolojik özellikleri incelenmiştir. I - V yaş grupları arasındaki 1232 bireyin \%33,87' dişi, \%\% 66,13' sı erkek olup, D:E=0.51:1 olarak bulunmuştur ( $p>0.05)$. Boy-ağlrlı ilişkisi ve büyüme eşitlikleri $\left.W=0.044 L^{2.470}, L_{t}=18.6\left[1-e^{0.24(t-3.3)}\right]\right), \Phi=4.4$ olarak hesaplanmıştır. Aylara göre kondüsyon faktörü değerleri incelendiğinde, ortalama en yüksek değere Haziranayında rastlandı̆̆ saptanmıştır. T. mediterraneus populasyonunun üreme döneminin Temmuz ayında en yüksek değere ulaşarak, Nisan- Eylül aylarl arasında olduğu belirlenmiştir. Türün mutlak yumurta verimliliği-toplam boy $F=1.368 x T L^{2.75}$ olarak tespit edilmiştir. Toplam ölüm (Z), doğal ölüm, ve balıkçılıktan gelen ölüm oranı de ğerleri sirasıyla, $Z=1.36 y_{l} l^{-1}, M=0.33 y_{l} l^{-1}, F=1.03 y_{l} l^{-1}$ olarak hesaplanmiştır. Sömürme oranı ise, E= 0.76 olup, populasyonun aşırı tüketildiği söylenebilir.

Anahtar sözcükler: Trachurus mediterraneus, Bandırma Körfezi, büyüme, üreme.

\footnotetext{
*Hatice TORCU KOÇ, htorcukoc@balikesir.edu.tr, https://orcid.org/0000-0003-0678-1509 Zeliha ERDOĞAN, zaka@balikesir.edu.tr, https://orcid.org/0000-0002-5725-4402
}

Bu çalışma, BAP tarafından desteklenen 2013/81 nolu “Marmara Denizi, Bandırma Körfezi'nde yaşayan sarıkuyruk istavrit [(Trachurus mediterraneus (Steindachner, 1868)] populasyonunun biyolojik özelliklerinin İncelenmesi” konulu projenin bir kısmını oluşturmaktadır. 


\title{
Some population parameters of the Mediterranean horse mackerel [(Trachurus mediterraneus (Steindachner, 1868)] population living in Bandirma Bay, The Sea of Marmara
}

\begin{abstract}
A total of 1232 horse mackerel T.mediterraneus (Steindachner, 1868) were collected from Bandırma Bay, Sea of Marmara between September 2013 and December 2015 in order to evaluate some information on length-weigth frequencies, age-sex distribution and ratios, Von Bertalanffy growth equation, length-weight relationship, condition factor feeding of this species. The population was composed of five age-classes (I-V) .Of 1232 specimens, female was of $33.87 \%$ and male $\% 66.13 \%$ with sex ratio as $F: M=0,51:(p>0.05)$. Total length and total weight of sampled fish ranged from 9.77 to $17.6 \mathrm{~cm}$ and 5.67 to $44.0 \mathrm{~g}$., respectively. Length-weight relationship and the von Bertalanfy growth parameter were estimated as $\left.W=0.044 L^{2.470}, L_{t}=18.6\left[1-e^{0.24(t-3,3)}\right]\right)$, respectively. Besides, growth performance index $(\Phi)$ of this species were determined as 4.4 for all individuals, As condition factor value was examined, it was determined that the highest value in CF reached in June. The spawning period of T. mediterraneus occurred between April and Eylül with a peak in July. Absolute fecundity- total length relationship was estimated as $F=1.368 x T L^{2.75}$. It was estimated that total $(Z)$ mortality , natural $(M)$ mortality, and fishing $(M)$ mortality rates were of $Z=1.36$ year ${ }^{-1}, M=0.33$ $y l l^{-1}, F=1.03 y_{l} l^{-1}$. As exploitation rate was estimated as $E=0.76$, it can be said that the population was consumed highly.
\end{abstract}

Key words: Trachurus mediterraneus, Bandırma Bay, growth, reproduction.

\section{Giriş.}

Trachurus mediterraneus İngiliz Kanalı'ndan Akdeniz ve Karadeniz'e kadar dağılım gösteren yar1-pelajik bir türdür $[1,2]$ Marmara Denizi'nin Karadeniz ve Akdeniz Su sistemleri arasında yer alarak, bir iç deniz özelliği taşıması bu bölgenin göçmen balıklar açısından zengin olmasını sağlanmaktadır [3]. Su Ürünleri İstatistikleri [4]'e göre, Marmara Denizi'ndeki yıllık ortalama 44.447 ton ürünün büyük bir kısmını (\%44) başta hamsi olmak üzere diğer önemli pelajik türlerden istavrit (\%15) ve sardalya (\%11) oluşturmaktadir.

Yabancı araştırmcılar tarafından türün biyolojisi üzerine bazı çalışmalar bulunmaktadır. Arneri ve Tangerini [5], Arneri [6], Wysokinski [7], Karlou-Riga [8], Koutrakis ve Tsikliras [9], Jardas ve ark. [10]. Ülkemizde ise, Demir [11] ve Akşiray [12] istavrit türlerinin denizlerimizdeki dağılımını bildirmişlerdir. Şahinoğlu [13] ve Şahin ve ark. [14] türün bazı biyolojik özelliklerini incelemișlerdir. Kayalı [15], Doğu Karadeniz'de sarıkuyruk istavritin bazı populasyon parametrelerini çalışmıştır. Turan [16] Trachurus mediterraneus'un morfometrik ve meristik özelliklerini kullanarak Karadeniz, Ege, Marmara ve Doğu Akdeniz'deki istavrit stoğunun yapısını incelemiştir. Kasapoğlu [17], Bostanc1 [18] ve Atılgan ve ark. [19] Marmara Denizi, ve Doğu Karadeniz'deki sarıkuyruk istavritlerin otolit yapısı ve bazı populasyon özelliklerini araştırmışlardır. Şahin ve ark. [20] Doğu Karadeniz'ndeki sarıkuyruk istavritlerin büyüme ve 
gonadosomatik indeksini incelemişlerdir. Marmara Denizi’nin önemli pelajik türü olan sarıkuyruk istavrit gerek besin zincirindeki yeri, gerekse stoklarının durumu açısından ekonomik önemi yüksek olan balık türlerinden biridir. Yapılan literatür araştırmalarında Bostancı [18] tarafından Marmara Denizi'nde yapılan bir populasyon çalışması dışında, bu türün populasyon biyolojisini ortaya koyacak kapsamlı bir çalışmanın eksikliği göze çarpmaktadır.

Bu çalışma ile Bandırma Körfezi'nde dağılım gösteren T.mediterraneus'un büyüme ve beslenme özelliklerinin daha fazla bireyle incelenmesiyle ortaya konan sonuçların, günümüzde ve gelecekteki sarıkuyruk istavrit stoklarının yönetimine katkıda bulunulacağı düşünülmektedir.

\section{Materyal ve yöntem}

\section{1. Örneklerin elde edilmesi ve de ğerlendirilmesi}

Toplam 1232 sarıkuyruk istavrit bireyi 2013-2015 y1lları arasında Bandırma Körfezi'nden $\left(40^{\circ} 25^{\prime} 0^{\prime \prime}\right.$ Kuzey ile $28^{\circ} 0^{\prime} 0^{\prime \prime}$ Doğu) girgır ve algarna ile rastgele örnekleme yöntemi ile aylık olarak elde edilmiştir. Örneklerin total boy ölçümleri, \pm 1 $\mathrm{mm}$ hassasiyetli kumpas ile yapılmış ve $0.5 \mathrm{~cm}$ 'lik boy sınıflarına alınarak incelenmiştir. Vücut ağırlığ ise \pm 0.01 gr hassasiyetli terazi ile ölçülmüştür. Yaş tayinleri için otolitlerden yararlanılmıştır [21, 22]. Elde edilen bireylerin boy ağırlık ilişkisinin incelenmesinde $W=a \cdot L^{b}$ şeklinde verilen allometrik büyüme denkleminden yaralanılmıştır [23]. Büyüme ilişkisinin matematiksel olarak hesabında, von Bertalanffy tarafından geliştirilen büyüme eşitliğgi: $\mathrm{L}_{\mathrm{t}}=\mathrm{L}_{\infty}\left[1-\mathrm{e}^{-\mathrm{k}(\mathrm{t}-\mathrm{t})} \mathrm{o}\right]$ ve büyüme performansı indeksi için ise, $\Phi=\log 10 \mathrm{k}+2 \log 10 \mathrm{~L}_{\infty}$ denkleminden yaralanılmıştır [24]. Besililik durumunun bir göstergesi olarak, kondisyon faktörünün hesaplanmasında; $\mathrm{K}=$ $\left(\mathrm{W} / \mathrm{L}^{\mathrm{b}}\right) * 100$ eşitliği kullanılmıştır [23]. Örneklerin eşey durumları eşeysel olgunluk safhaları dikkate alınarak, makroskobik olarak yapılmıştır [23, 25]. Örnekleme periyodunda örneklerdeki dişi-erkek oranları arasında istatistiksel açıdan fark olup olmadığını belirlemek amacı ile t-test uygulanmıştır [26]. Gonadosomatik indeks değerlerinin hesaplanmasında; GSI: (Gonad ağırlığı/Gonadsız Vücut Ağırlığı) * 100, eşitliğinden faydalanmıştır [23]. Sarıkuyruk istavrit balıklarının yumurta verimliliklerini hesaplamak için dişi bireylerin ovaryumlarından ön, orta ve arka kısımlarından olmak üzere 3 ayrı yerinden alt örnek alınmıştır. Daha sonra, örneklenen yumurtalar binoküler mikroskopta (10x10), 1/10 ölçekli mikrometrik oküler kullanmak suretiyle incelenmişlerdir. Böylelikle alt örnekteki yumurta adedi tahmin edilmiştir. Alt örnekteki yumurta adedi değeri kullanılarak, ilgili bireyin ovaryumundaki toplam yumurta verimliliği (F) hesaplanmıştır. Fekondite-boy ilişkisi Üssi bir ilişki olup $\left(\mathrm{F}=\mathrm{a}^{*} \mathrm{~L}^{\mathrm{b}}\right)$ şeklindedir [23].. Toplam ölümün üssi katsayısı olarak ifade edilen Z'nin tahmini Beverton ve Holt [27] tarafından geliştirilen $\mathrm{Z}=\mathrm{K}^{*}\left[(\mathrm{~L} \infty-L) /\left(L-\mathrm{L}^{\prime}\right)\right]$ ile doğal ölüm $(\mathrm{M})$ oranı ise; Ursin'inin $\mathrm{M}=\mathrm{W}^{(-1 / b)}$ ile hesaplanmıştır. Buradan, $\mathrm{Z}$ and $\mathrm{M}$ değerleri kullanılarak, balıkçılıktan gelen ölüm oranı $(\mathrm{F}), \mathrm{F}=\mathrm{Z}-\mathrm{M}$, Sömürme oranı $\mathrm{E}=\mathrm{F} / \mathrm{Z}$ hesaplanmıştır [23].

\section{Bulgular}

\subsection{Boy ve ăğılık dăğlımı}

Örnekleme periyodunda Trachurus mediterraneus türüne ait 1232 adet birey elde edilmiştir. Türün genel boy dağılımı incelendiğinde; $0.5 \mathrm{~cm}$ 'lik boy gruplarına ayrılan 
örneklerin 9.5-17.5 cm total boylar arasında ve bireylerin \% $12.8^{\prime}$ 'lük oranla $14.0 \mathrm{~cm}$ 'lik boy grubunda en fazla olduğu saptanmıştır (Şekil 1).

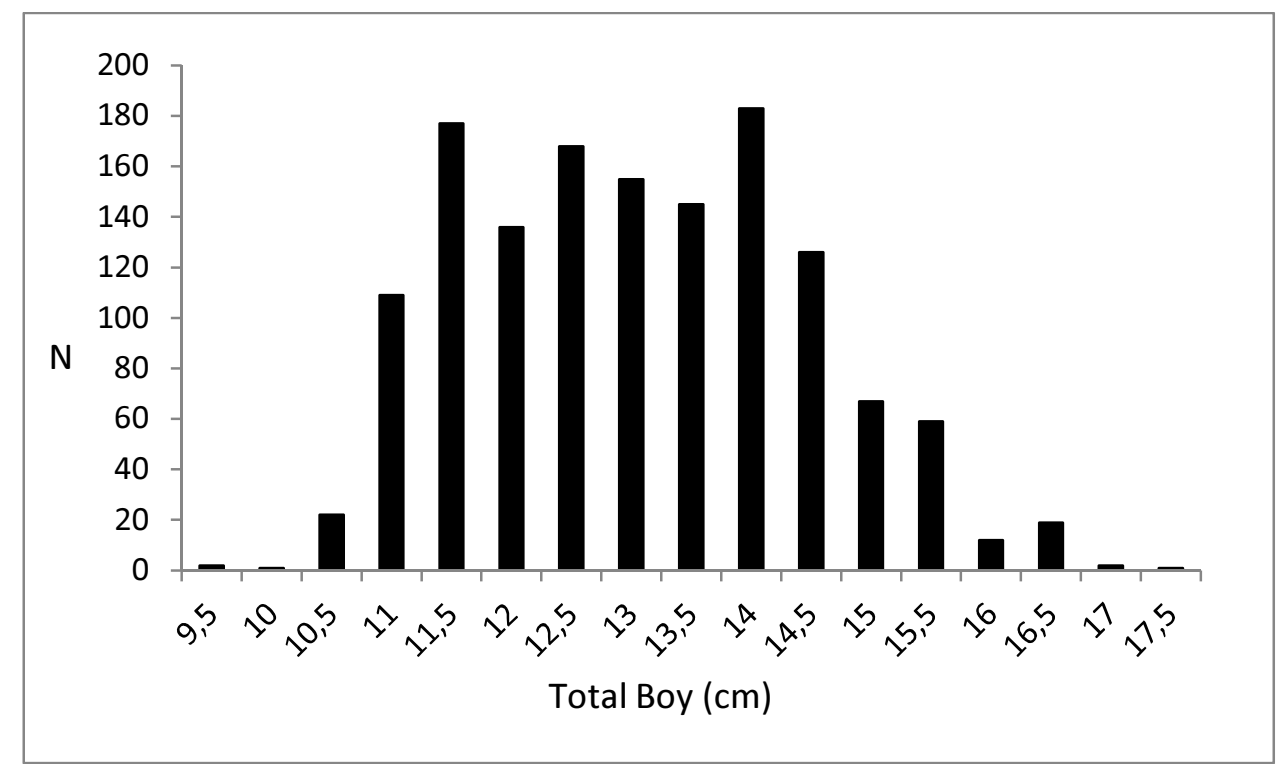

Şekil 1. Trachurus mediterraneus bireylerinin genel boy dağılımı.

Ağırlık açısından bakıldığında ise örneklerin 5.67-44.0 gr arasında dağılım gösterdiği ve \% 29.4'ının 15.0 gr' lık bireylerden oluştuğu gözlenmiştir (Şekil 2).

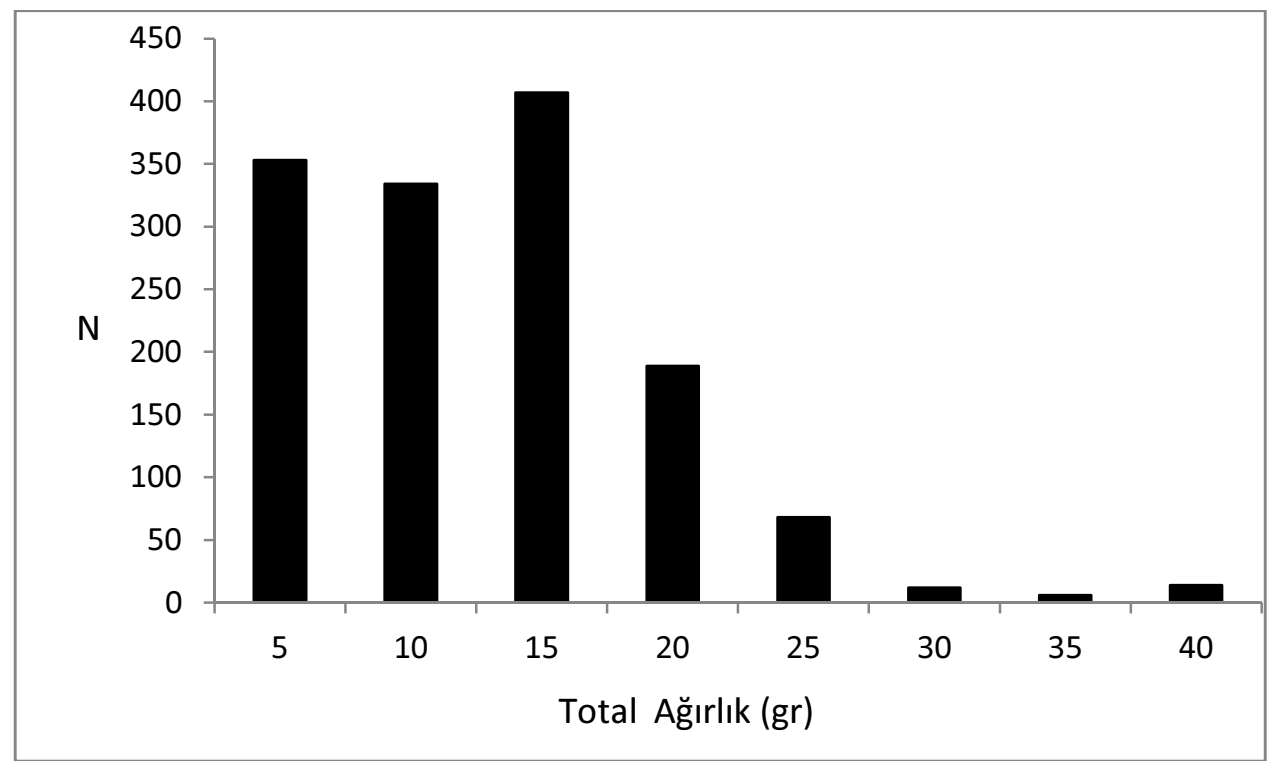

Şekil 2. Trachurus mediterraneus bireylerinde genel ağırlık dağılımı.

\subsection{Eşey dăğlımı}

Araştırma periyodunda yakalanan 1232 T. mediterraneus bireylerinde eșey ayrımı sonucunda 417'sinin (\% 33.87) dişi, 815'inin ise (\% 66.13) erkek olduğu ve istatistiksel açıdan önemli fark olduğu saptanmıştır ( $\mathrm{D}: \mathrm{E}=0.51: 1),(\mathrm{p} \leq 0.05)$ (t-test) (Şekil 3). 


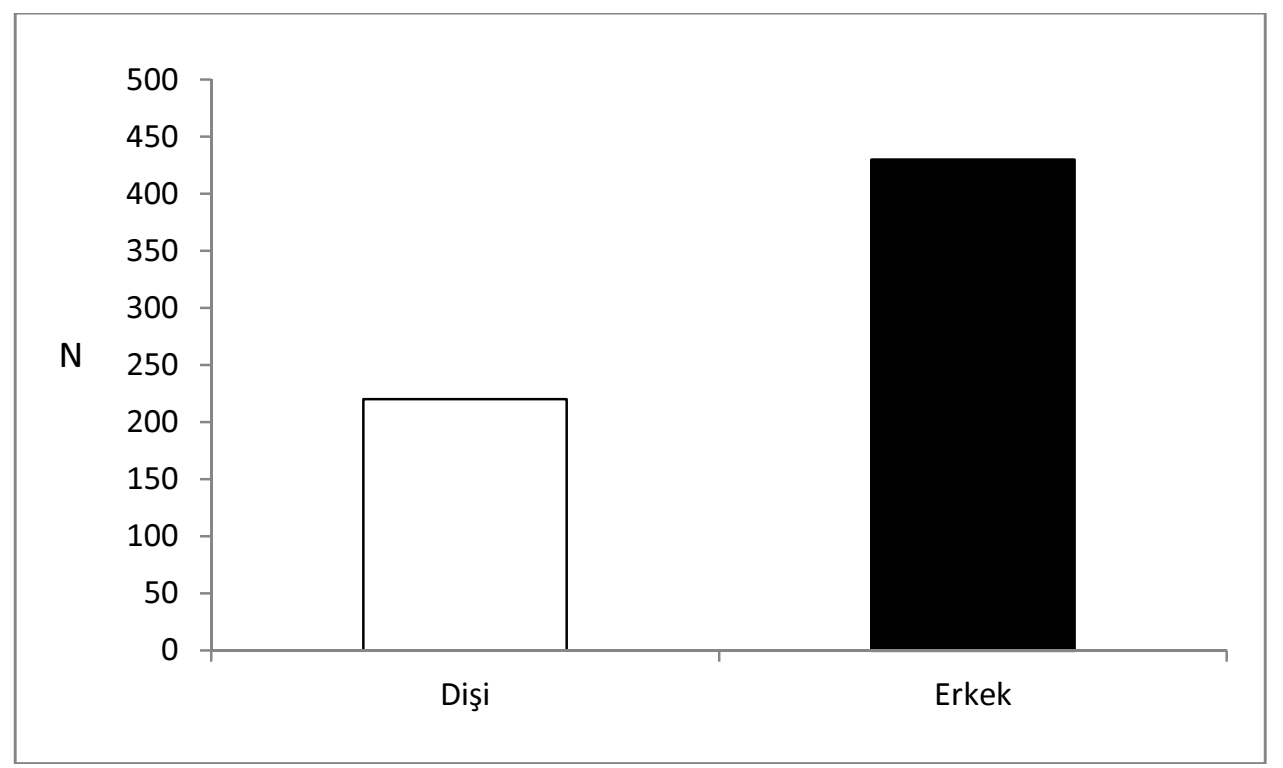

Şekil 3. Trachurus mediterraneus bireylerinin eșey oranı.

\subsection{Yaş kompozisyonu-}

Araştırma bölgesinden yakalanan T. mediterraneus türüne ait örnekler, 1-V yaş grupları arasında dağılım göstermiştir. (Şekil 4).

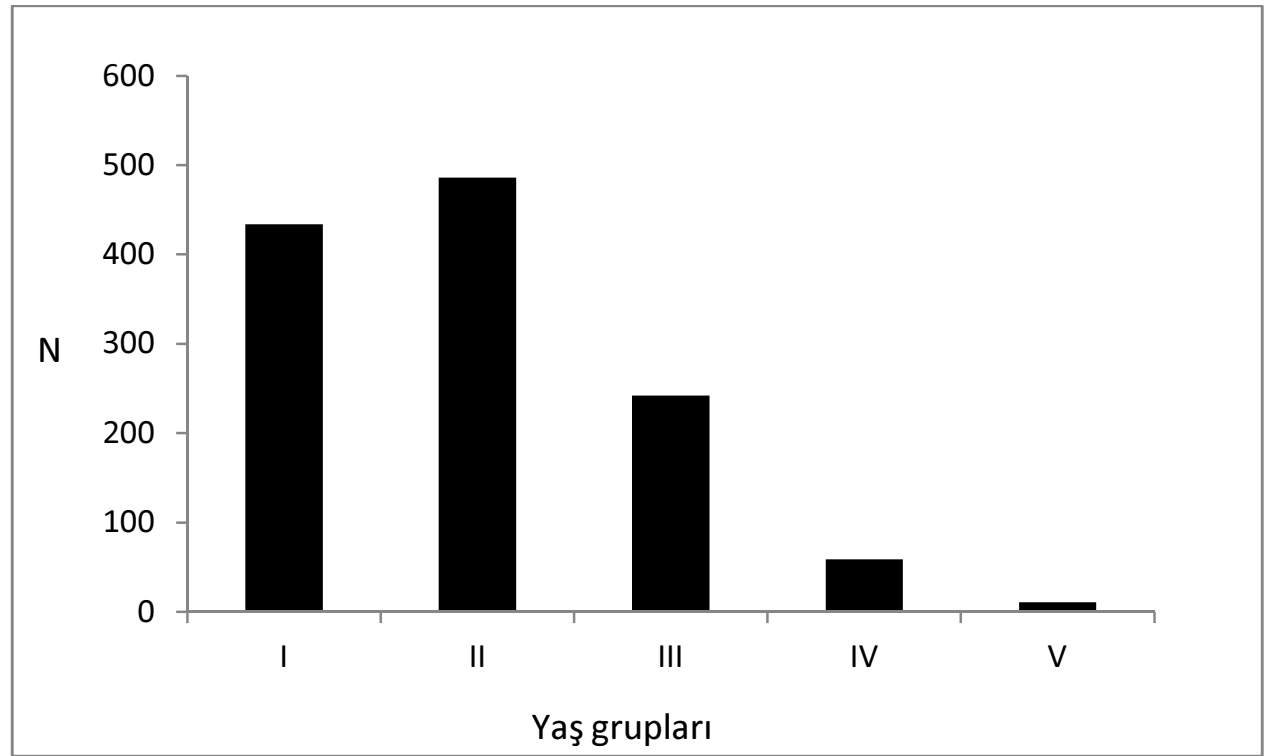

Şekil 4. Trachurus mediterraneus bireylerinin yaş dağılımı.

\subsection{Yaş-boy ilişkisi}

Otolitlerden yapılan yaş okumaları sonucunda Bandırma Körfezi'nden elde edilen $T$. mediterraneus bireylerinin I yaş grubunda $12.06 \mathrm{~cm}$, II yaş grubunda $13.40 \mathrm{~cm}$, III yaş grubunda ise $14.58 \mathrm{~cm}$, IV yaş grubunda ise 15.40 ve V yaş grubunda $16.07 \mathrm{~cm}$ boy gruplarına ulaştıkları tespit edilmiştir. Tüm bireyler için von-Bertalanffy büyüme denklemive büyüme performansı: $L_{i}=18.6\left[1-\mathrm{e}^{-0.24(++3.3)}\right], \Phi^{\prime}=4.4$ olarak hesaplanmıştır. 


\subsection{Boy-ăğrlık ilişkisi}

Tüm sarıkuyruk bireylerinin b değerine bakıldığında populasyonun negatif allometrik büyüme gösterdikleri belirlenmiştir (Şekil 5).

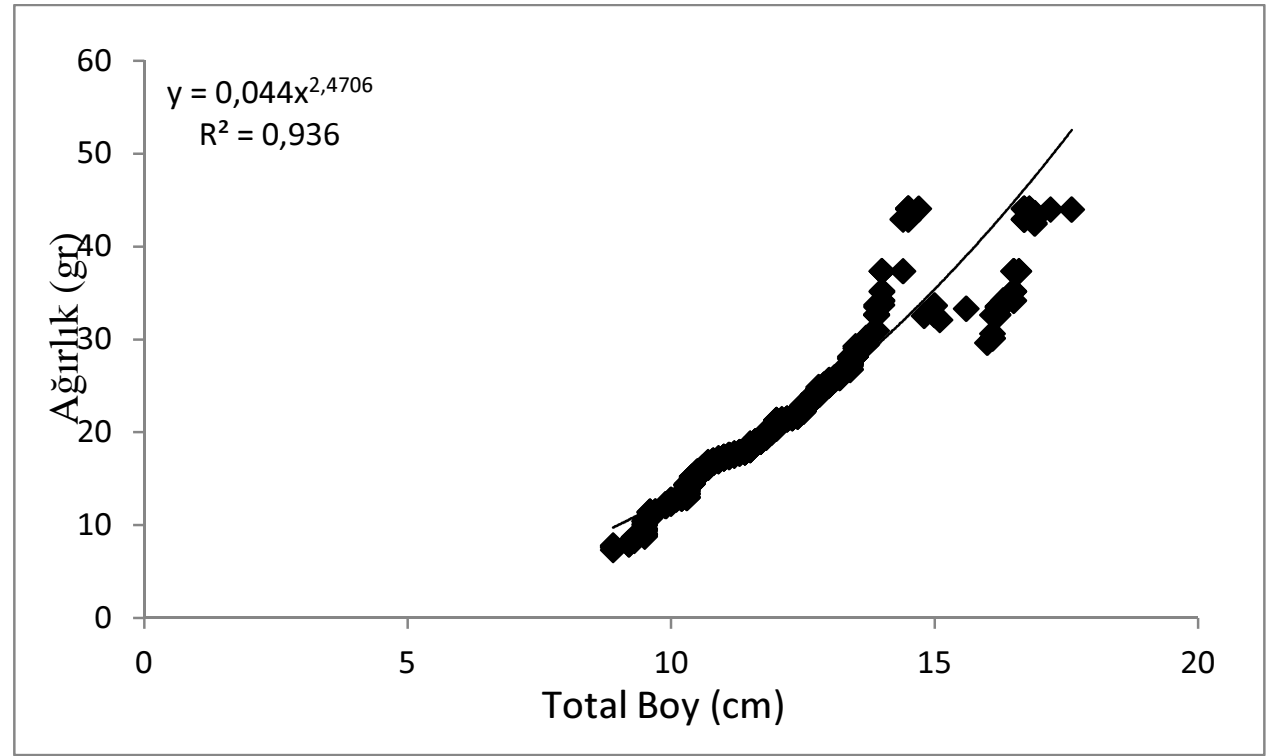

Şekil 5. Trachurus mediterraneus bireylerinin genel boy-ağırlık ilişkisi.

\subsection{Kondisyon faktörï}

Aylara göre kondisyon faktörü değerleri incelendiğinde, ortalama en yüksek değere Ekim ayında, ortalama en düşük değere ise Eylül ve Aralık aylarında ulaştığı tespit edilmiştir (Şekil 6).

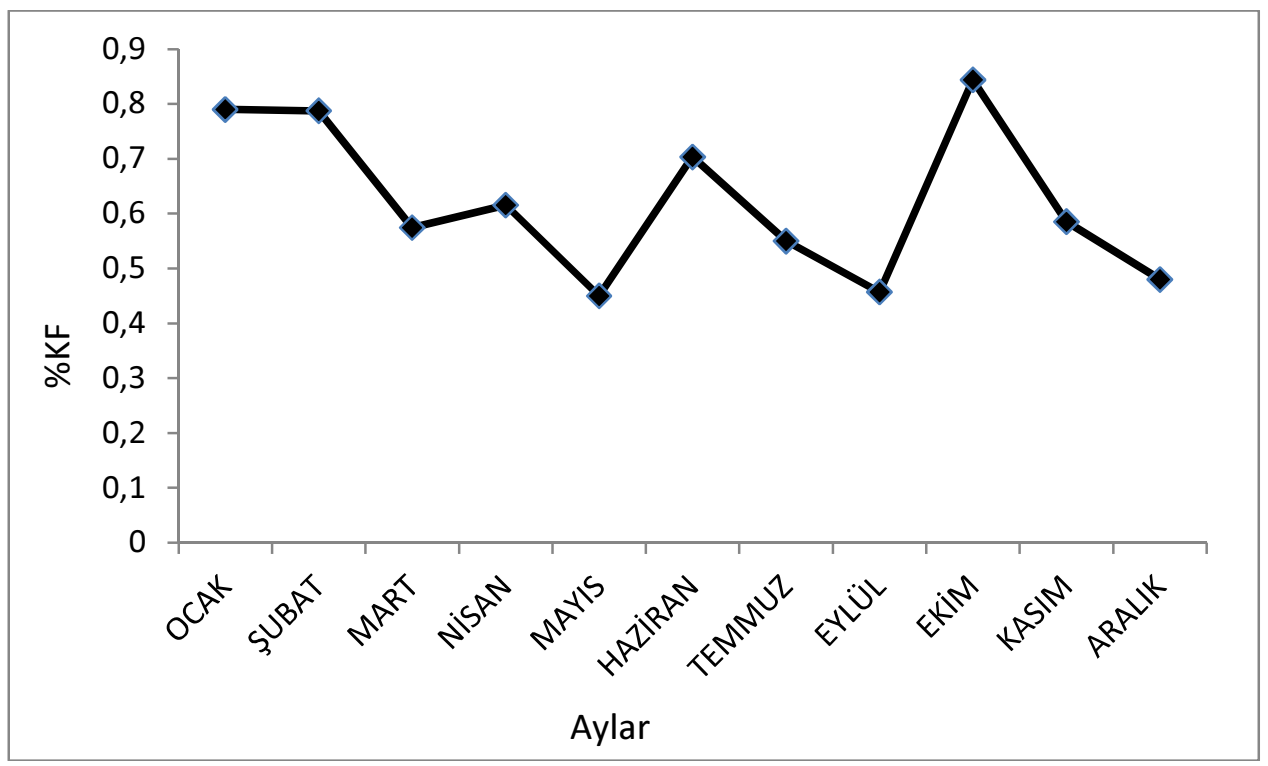

Şekil 6. Trachurus mediterraneus bireylerinin aylara göre kondisyon faktörü değerleri.

\subsection{Gonadosomatik indeks (GSI)}

GSİ, balıklarda gonat gelişimi ve üreme döneminin belirlenmesinde kullanılan başlıca parametrelerden biridir. Bu çalışmada T. mediterraneus bireylerinde, yumurtlamanın 
Nisan-Eylül ayları arasında gerçekleştiği, Temmuz ayında ise en yüksek değerine ulaştığı tespit edilmiştir (Şekil 7).

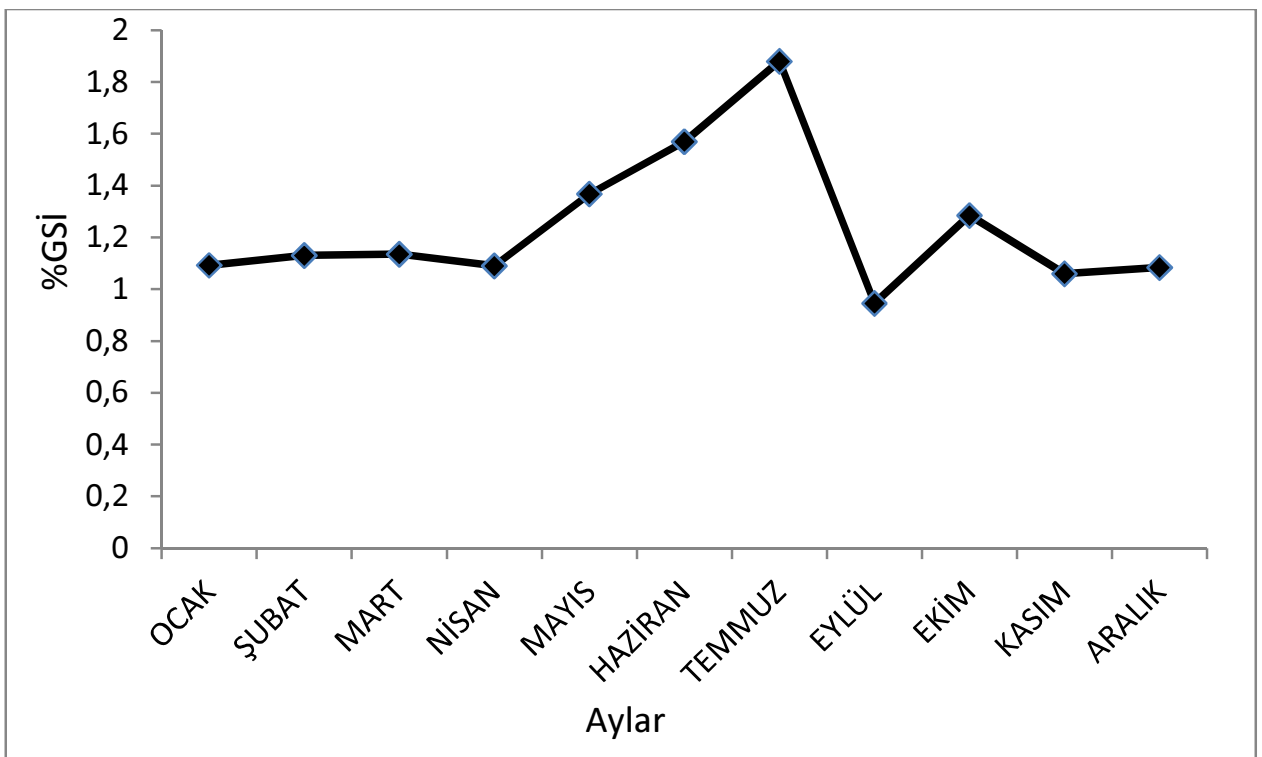

Şekil 7. Trachurus mediterraneus bireylerinin aylara göre gonadosomatik indeks değerleri.

\subsection{Fekondite (Mutlak yumurta verimliliği)}

Yumurta verimliliğini saptamada kullanılan bireylerin boy ölçüm değerleri 12.5-15.8 $\mathrm{cm}$ arasında değişmektedir. Yumurta verimliliği-boy arasında tam logaritmik bir ilişkinin bulunmuş olması, boyu bilinen bir ergin dişinin ortalama yumurta verimliliğinin hesaplanabileceğini göstermektedir. Diğer bir deyişle, boy arttıkça nispeten yumurta verimliliği de artmaktadır (Şekil 8).

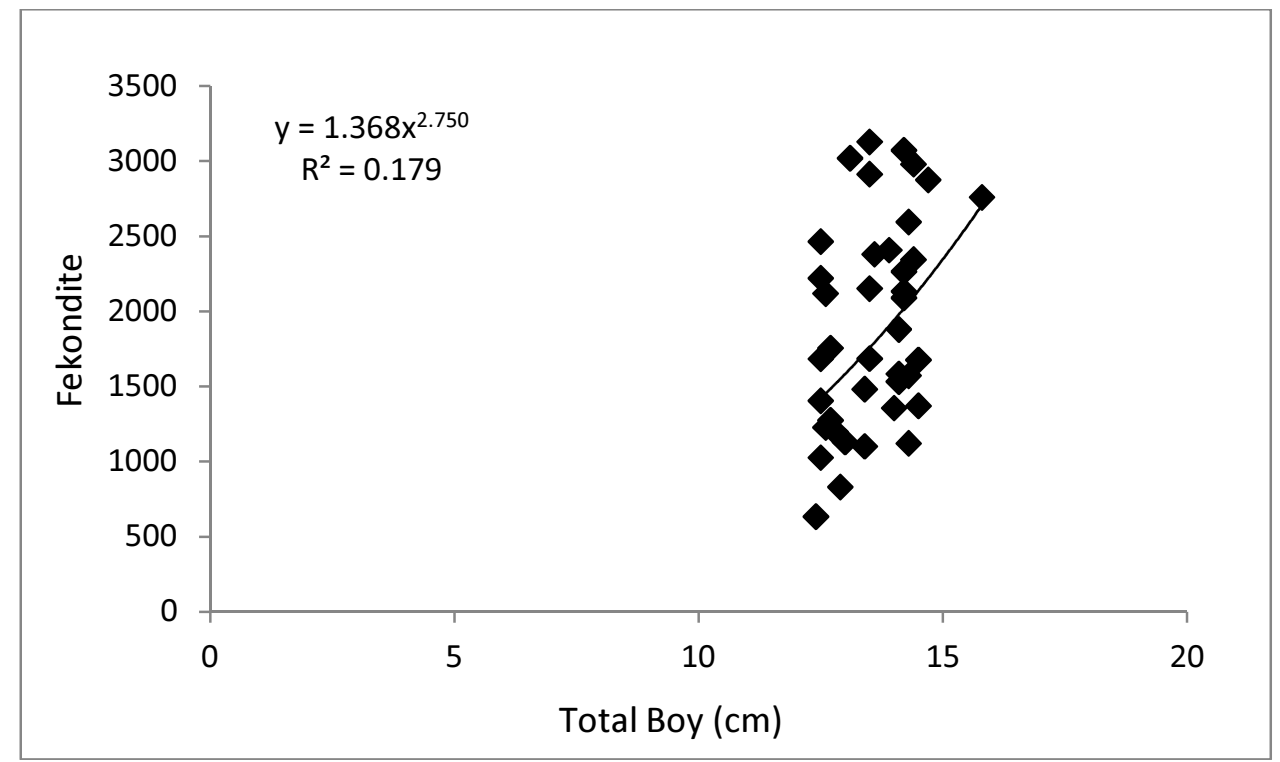

Şekil 8. Dişi Trachurus mediterraneus bireylerinin boya göre fekondite değerleri. 


\subsection{Mortalite (Ölüm)}

Sarıkuyruk istavrit bireyleri için toplam ölüm $\mathrm{Z}=1.36 \mathrm{yll}^{-1}$, doğal ölüm oranı $\mathrm{M}=0.33$ $\mathrm{y}_{1}{ }^{-1}$, balıkçılıktan gelen ölüm oranı $\mathrm{F}=1.03 \mathrm{y}^{-1}{ }^{-1}$, sömürme oranı ise $\mathrm{E}=0.76$ olarak hesaplanmıştır.

\section{Tartışma}

Bu çalışma, Bandırma Körfezi'nden T. mediterraneus türüne ait 1232 birey üzerinde gerçekleştirilmiş olup, populasyonun bazı biyolojik özellikleri araştırılmıştır. Araştırma periyodunda elde edilen bireylerin total boy değerleri 9.7-17.6 cm, ağırlık değerleri 5.67-44.0 gr arasında dağılım göstermiştir (Şekil1, 2). Diğer araştırmacıların buldukları toplam boy değerlerine bakıldığında, Viette ve ark. [28] 9.8-38.3 cm; Karakulak ve ark. [29] 15.5-24.3 cm; Petrakis ve Stergio [30] 17,3-34,2 cm; Santic ve ark. [31] 14.8-39.1 cm, Yankova ve ark. [32] 11.0-17.5 cm; Özdemir ve ark. [33] Karadeniz'de 7.8-18.0 cm; Pesic ve ark. [34] 8.9-31.3 cm; Demirel ve Yüksek [35] 13.5-19.5 cm aralığında vermişlerdir. Türün farklı populasyonlarına ait boy değerlerine bakıldığında, bölgelerin biyo-ekolojik özellikleri, özellikle sicaklık, ortamdaki besin miktarı, örnekleme teknikleri farklılıklar oluşturabilir. Araştırmada elde edilen 1232 bireyin 417' sinin (\% 33.87) dişi, 815'inin ise (\% 66.13) erkek olduğu gözlenmiştir ( $\mathrm{D}: \mathrm{E}=0.51: 1)$ (t-test, $\mathrm{p} \leq$ 0.05) (Şekil 3). Pesic ve ark. [34]'nın çalışmasında üreme dönemi dışında yapmış olduğu ayırımda dişilerin oranının erkeklere göre fazla olduğunu, bu durumun istatistiksel açıdan önemli olduğunu belirtmiştir. $\mathrm{Bu}$ durum bizim çalışmamızla uygunluk göstermektedir. Araştırma bölgesindeki T. mediterraneus bireylerinin I ila V yaş grupları arasında olduğu gözlenmiştir (Şekil 4). Körfez'deki sarıkuyruk istavrit örneklerinin $(\mathrm{N}=1232)$ ulaştığı maksimum yaş grubu $\mathrm{V}$ olarak saptanmıştır. Diğer araştırmacıların maksimum yaş değerlerine bakıldığında; Viette ve ark. [28] VI, Arneri ve Tangerini [5] III, Yankova ve ark. [36] VII olarak bildirmişlerdir. Ancak, örnekleme teknikleri ve bölgelerinin iklimsel farklılıklarının meydana getirebileceği büyüme faklılıkları populasyonlarda gözlenebilir. Bandırma Körfezi'nde T. mediterraneus populasyonunun yaş gruplarına bağlı von Bertalanffy boyca büyüme eşitlikleri de Tablo 1 'de verilmiştir.

Tablo 1. Trachurus mediterraneus bireylerinin farklı bölgelerde saptanan von Bertalanffy büyüme parametreleri.

\begin{tabular}{l|l|l|l|l|l|l}
\hline Bölge & Boy aralığı & Yaş & $\mathbf{L} \infty$ & $\mathbf{k}$ & $\mathbf{t}_{\mathbf{0}}$ & $\Phi$ \\
\hline Lucio [37] & & & 52.01 & & & \\
\hline Şahin ve ark. [14] & & $1-6$ & 18.36 & 0.43 & -0.598 & \\
\hline Prodonov ve ark. [38] & - & & 19.25 & 0.35 & -0.595 & - \\
\hline Karlou-Riga [8] & & & 37.24 & 0.326 & -0.842 & - \\
\hline Raykov ve Yankova [39] & - & $1-5$ & 19.99 & 0.31 & -0.491 & - \\
\hline Yankova ve ark. [32] & & $0-6$ & 19.60 & 0.30 & 0.877 & - \\
\hline Yankova [36] & & & 18.73 & 0.61 & - & - \\
\hline Bandırma Körfezi (2013-2015) & $9.7-17.6$ & & 18.6 & 0.24 & -3.3 & 4.4 \\
\hline
\end{tabular}

Bandırma Körfezi'nde $T$. mediterraneus populasyonunun $\mathrm{L}_{\infty}$ değeri $18.60 \mathrm{~cm}$ olup, diğer araştırmacıların sonuçlarıyla karşılaştırıldığında, Şahin ve ark. [14]'nın Karadeniz ve Yankova [37]'nın Adriyatik için bildirdikleri $L_{\infty}$ değerleri dişında, diğer 
araştırmacıların bulgularının bizim değerlerimizden yüksek olduğu gözlenmiştir. $\mathrm{L}_{\infty}$ değeri, yaş gruplarının ortalama boylarına göre hesaplanmasından dolayı, aynı türün farklı bölgelere ait populasyonlarına ve örnek sayısına göre değişebilmektedir. Fi-üssü $(\Phi)$ değerlerine bakarak büyüme parametrelerini karşılaştırabileceğimiz bir çalışma bulunmamakla beraber, Bandırma Körfezi'ndeki büyümenin yüksek olduğu görülmektedir. Bandırma Körfezi'nde T. mediterraneus bireylerinin ölçümle elde edilen ağırlıklarının ise, 5.67-44.0 gr arasında dağılım gösterdiği saptanmıştır. Özdemir ve ark. [33] ve Demirel ve Yüksek [35] Karadeniz ve Marmara Denizi'nin Kuzey Doğusunda yaptıkları çalışmada ağırlık dağılımlarını sırasıyla 3.6-49.9 gr ve 18.0-64.0 gr. olarak vermişlerdir. Tüm populasyon için hesaplanan korelasyon katsayıları $\left(\mathrm{R}^{2}\right)$ değerin bire yakın oluşu, boy ile ağırlık arasında iyi bir ilişkinin olduğunu göstermektedir. b değeri ise 2.47 olarak negatif allometrik bir artış olduğunu göstermektedir (Şekil 5). Farklı bölgelerde yapılan çalışmaların boy-ağırlık ilişkisi parametreleri Tablo 2'de gösterilmiştir.

Tablo 2. Trachurus mediterraneus bireylerinin farklı bölgelerde saptanan boy-ağırlık ilişkisi parametreleri.

\begin{tabular}{l|l|l|l|l|l|l}
\hline \multicolumn{1}{c|}{ Araştırmacılar } & \multicolumn{1}{c|}{ Bölge } & \multicolumn{1}{c|}{ N } & \multicolumn{1}{c|}{ Boy } & \multicolumn{1}{c|}{$\mathbf{a}$} & \multicolumn{1}{c|}{ b } & $\mathbf{R}^{\mathbf{2}}$ \\
\hline Arneri ve Tangerini [5] & Adriyatik & 560 & $8.40-34.0$ & 0.0055 & 3.15 & \\
\hline Petrakis ve Stergio [30] & Greek & 191 & $17.3-24.1$ & 0.01448 & 2.824 & 0.92 \\
\hline Dulcic ve Kraljevic [40] & Adriyatik & 17 & $25.5-34.5$ & 0.0152 & 2.996 & \\
\hline Pronadov ve ark. [38] & Bulgarian B. & & & 0.3220 & & \\
\hline Merella ve ark.[41] & Balear & 232 & $3.9-24.4$ & 0.0138 & 2.760 & - \\
\hline Şahin ve ark.[14] & Karadeniz & 600 & $7.4-14.5$ & 0.0048 & 3.2188 & \\
\hline Genç ve ark.[42] & Karadeniz & & $6.5-17.0$ & 0.0075 & 3.02 & \\
\hline Moutopoulos ve Stergio [43] & Greek & 191 & $17.3-34.1$ & 0.0144 & 2.824 & \\
\hline Koutrakis ve Tsikliras [9] & Greek & 21 & $11.7-25.7$ & 0.0122 & 2.870 & \\
\hline Kasapoğlu [17] & Karadeniz & 1312 & $9.2-19.0$ & 0.0089 & 2.955 & \\
\hline Santic ve ark. [31] & Adriyatik & 1245 & $14.8-39.1$ & 0.003 & 3.293 & \\
\hline Karakulak ve ark. [29] & Ege Denizi & 264 & $10.5-24.3$ & 0.0113 & 2.897 & \\
\hline Kalaycı [44] & Karadeniz & & & & 3.094 & \\
\hline Samsun ve ark. [45] & Karadeniz & & & 0.0063 & 3.0931 & \\
\hline Bostanc1 [18] & Marmara & 158 & $7.9-16.5$ & 0.0115 & 2.9367 & \\
\hline Yankova ve ark.[32] & Bulgarian B. & 1995 & & & 3.3046 & \\
\hline Özdemir ve ark. [33] & Karadeniz & - & $7.8-18.0$ & 0.0074 & 3.0445 & 0.96 \\
\hline Santic ve ark. [31] & Adriyatik & 1411 & $9.2-39.0$ & 0.0030 & 2.999 & \\
\hline Pesic ve ark. [34] & Montenegrin & 190 & $8,9-31,3$ & 0.0073 & 3.01245 & 0.9489 \\
\hline Yankova [36] & Bulgarian & & & & & \\
\hline Yankova [44] & Bulgarian & 2900 & $9,5-18,0$ & 0.00678 & 3.2773 & 0.9833 \\
\hline Bu çalışma (2013-2015) & Bandırma K. & 1232 & $9.7-17.6$ & 0.044 & 2.47 & 0.9 \\
\hline
\end{tabular}

b katsayıları diğer çalışmalarda 2.76-3.30 değerleri arasında değişmektedir. Balear adalarından elde edilen sarıkuyruk istavrit populasyonunun negatif allometrik büyüme göstermesi bulgularımızı desteklemektedir [41] (Tablo 2). Bu sonuçlara göre Bandırma Körfezi sarıkuyruk istavritlerinin ortalama düzeyde bir boy ağırlık büyümesi gösterdiğini söylenebilir. Araştırma bölgesindeki T.mediterraneus populasyonuna ait kondisyon faktörü incelendiğinde en yüksek ortalamaya tüm bireylerde Ekim ayında 0,88 iken, en düşük değere ise Eylül ayında 0.45 olarak rastlanmıștır (Şekil 6). Aylık olarak gözlenen bu değişikliklerin üremenin dışında su sıcaklığına ve beslenmeye bağlı 
olduğu da düşünülmektedir. Boyca ve ağırlıkça büyümenin bir göstergesi olarak kabul edilen besililik derecesi veya kondisyon faktörü balığın üreme için en az enerji harcadığı aylarda en yüksek, üreme için enerji harcadığı aylarda en düşük değeri vermektedir. Ancak, kondisyon faktörü ile ilgili herhangi bir çalışma bulunmadığından, karşılaştırma yapılamamıştır. Aylık gonadosomatik indeks değerlerine bakıldığında, Nisan sonu ile birlikte hızlı bir artış gösteren GSİ değerinin, Temmuz ayında maksimum değere ulaştığı saptanmıştır (Şekil 7). Bulgularımız Viette ve ark. [28], Santic ve ark. [31], ve Demirel ve Yüksek [35], Adriyatik ve Marmara Denizindeki sarıkuyruk istavrit populasyonunun üreme dönemini desteklemektedir. Sarıkuyruk istavritin üreme dönemiyle ilgili diğer çalışmalara bakıldığında üreme dönemleri Tablo 3'de verilmiştir.

Tablo 3. Trachurus mediterraneus populasyonlarının farklı bölgelerdeki üreme dönemleri.

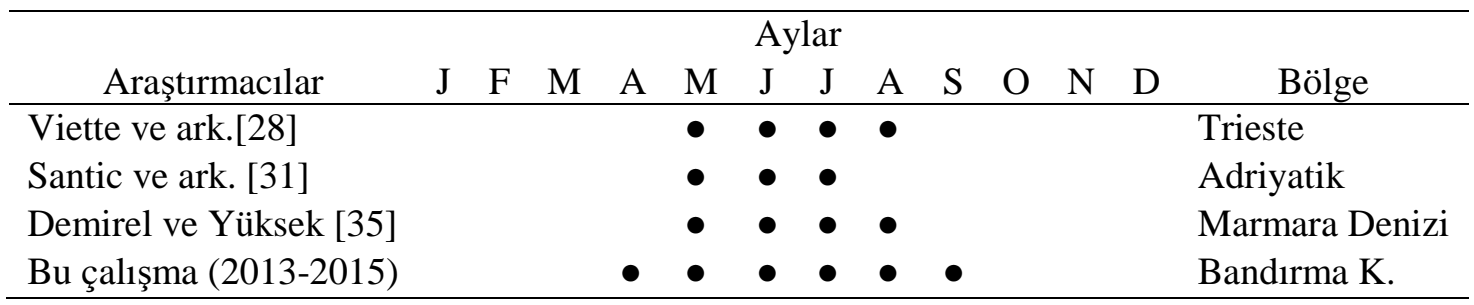

Bu çalışmada sarıkuyruk istavritin üreme dönemi, diğer çalışmalarla paralellik içindedir (Tablo 3). Balıklarda fekondite-boy arasındaki ilişki türden türe değişim gösterebilmektedir. Bu çalıșmada b değeri 3'e yakın olarak bulunmuștur. Diși bir balığın yumurta verimliliği türler arası rekabette olduğu kadar, aynı tür bireyleri arasında da değişiklik gösterebilmektedir [23]. Bununla beraber yumurta verimliliği, balıkların tükettiği besinlerin kalitesine ve miktarına bağlı olarak da değișebilir. Aynı zamanda, tüketilen besin miktarının kaynağına bağlı olarak artış ya da azalma gösterebilmektedir. [23]. Tüm bireyler için toplam ölüm $\mathrm{Z}=1.36 \mathrm{yll}^{-1}$, doğal ölüm $\mathrm{M}=$ $0,33 \mathrm{yll}^{-1}$ ve balıkçılıktan gelen ölüm $\mathrm{F}=1,03$ olarak hesaplanmıştır. Sömürme oranı ise, $\mathrm{E}=0.76$ olarak tespit edilmiştir. Buradan populasyonun oldukça sömürüldüğü ifade edilebilir. Bu çalışmadaki $\mathrm{Z}$ değerinin Bulgaristan kıyılarındaki sarıkuyruk istavritin toplam ölüm oranı, $\mathrm{Z}=1.42$ ile benzer olduğu [32], ancak, Kasapoğlu [17] tarafından Karadeniz'de bulunan $Z=3,73$ değerinden oldukça düşük olduğu görülmektedir. Aynı türler, predatörlerin ve rakiplerin yoğunluğuna bağlı olarak farklı bölgelerde farklı doğal ölüm oranlarına sahip olabilir ve bolluğu balıkçılıktan gelen baskılardan etkilenebilir [24].

\section{Sonuç}

Bandırma Körfezi ve çevresi balıkçılığında sarıkuyruk istavrit ekonomik değeri yüksek olan bir türdür. Bu çalışmanın gelecekte sarıkuyruk istavrit populasyonları üzerine yapılacak daha ayrıntılı çalışmalara bir başlangıç olacağı umut edilmektedir. Yapılacak araştırmalarla, balıkçılık açısından önemli bir getirisi olan körfez ekosistemi içerisinde yer alan ve sistemin elemanı olarak değerlendirilmesi, balıkçılık yönetimine önemli yararlar getireceği düşünülmektedir. Sonuçlarımız, Marmara Denizi, Bandırma Körfezi'ndeki balıkçılık stratejisinin sarıkuyruk istavrit avlanma periyodunun üreme periyodunu izleyecek şekilde planlanması gerektiğini göstermektedir. 


\section{Kaynakça}

[1] Whitehead, P.J.P., Bauchot, M.L., Hureau, J.C., Nielsen, J., Tortonese, E., (Editors). Fishes of the North-Eastern Atlantic and Mediterranean,Volume I, Paris, UNESCO, 517-1007 (1986).

[2] Fisher, W., Schneider, M., Bauchot, M.L., Fiches FAO d'identification des espèces pour les besoins de la pêche. Mediterranée et Mer Noire, zone de pêche 37. ONU pour l'alimentation et l'agriculture, Rome, 2: 1009-1029, (1987).

[3] Artüz, L., Türkiye pelajik balıkçılığına bakış (Pelagic fisheries of Turkey). et ve balık kurumu balıkçılık araştırma merkezi raporları, 2, 38-54, (1957).

[4] TÜİK. Fishery Statistics, Turkish Statistical Institute, 1-9, (2017).

[5] Arneri, E., Tangerini, P., Biological data, from the "Pipeta" expeditions, on Trachurus mediterraneus (Steindachner) in the Adriatic Sea. CGPM Troisieme consultation technique sur l'évaluation des stocks dans l'Adriatique, Fano, Annex O: 127-130, (1983).

[6] Arneri, E., Nota preliminare sulla biologia della specie del genere Trachurus (T. mediterraneus, T. trachurus, T. picturatus) in Adriatico, Nova Thalassia, 6 (suppl.), 459-464, (1984).

[7] Wysokinski, A., Horse mackerel age determination using otoliths ICSEAF collection of scientific papers of international commission of South-East Atlantic fisheries, 199-203, (1985).

[8] Karlou-Riga, C., Otolith morphology and age and growth of Trachurus mediterraneus (Steindachner) in the Eastern Mediterranean, Fisheries Research, 46, 69-82, (2000).

[9] Koutrakis, E.T., Tsikliras, A.C., Lengthweight relationships of fishes from three northern Aegean estuarine systems (Greece), Journal of Applied Ichthyology, 19, 258-260, (2003)

[10] Jardas, I., Šantić, M., Pallaoro, A., Biometric properties of Mediterranean horse mackerel Trachurus mediterraneus (Osteichthyes/ Carangidae) from the Central Adriatic Sea, Natural Croatian, 13(4), 343-355, Zagreb, (2004).

[11] Demir, M., On the eggs and larvae of the Trachurus trachurus (L.) and Trachurus mediterraneus (Stdhnr) from the Sea of Marmara and the Black Sea. CIESM, 16, 317-320, (1961).

[12] Akşiray, F., Türkiye deniz balıkları ve tayin anahtarı (marina fishes of Turkey and a key to species). İstanbul Üniversitesi Rektörlüğü Yayınları, İstanbul, 811, (in Turkish), (1987).

[13] Şahinoğlu, B., İzmir körfezinde karagöz istavrit (Trachurus trachurus L., 1758) ve sarıkuyruk istavrit (Trachurus mediterraneus Steindachner, 1868) balıklarının biyolojik özellikleri üzerine araştırmalar, Yüksek Lisans Tezi, Ege Üniversitesi., Su Ürünleri Bölümü, İzmir, 54, (1996).

[14] Şahin, T., Genç, Y., Okur, H., Karadeniz'in Türkiye Sularındaki İstavrit (Trachurus mediterraneus ponticus ALIEV) Populasyonunun Gelişme ve Üreme Özelliklerinin İncelenmesi, Doğa-Turk Journal of Zoology, 23, 321-327, (1997).

[15] Kayalı, E., Doğu Karadeniz'deki İstavrit (Trachurus mediterraneus, Steindchner, 1868) ve hamsi (Engraulis encrasicolus, Linneaus, 1758) balıklarının bazı populasyon parametreleri ve beslenme ekolojileri, Doktora Tezi, KTÜ, Fen Bilimleri Enstitüsü, Bal. Tekn. Müh. Anabilim Dalı, 238, Trabzon, (1998). 
[16] Turan, C., Stock Identification of Mediterranean horse mackerel (Trachurus mediterraneus) using morphometric and meristic characters, ICES Journal of Marine Science, 61, 774-781, (2004).

[17] Kasapoğlu, N., Doğu Karadeniz'deki istavrit (Trachurus mediterraneus, Steindachner, 1868) balığının stok yapısı ve populasyon parametreleri. Yüksek Lisans Tezi, Karadeniz Teknik Üniversitesi Fen Bilimleri Enstitüsü, 62, (2006).

[18] Bostanc1, D., Sarıkuyruk istavrit, Trachurus mediterraneus (Steindachner, 1868)'un otolit özellikleri ve bazı populasyon parametreleri, Frrat Üniversitesi Fen Bilimleri Dergisi, 21 (1), 53-60, (2009).

[19] Atılgan, E., Başçınar, N.S., Erbay, M., Doğu Karadeniz'deki istavrit, Trachurus mediterraneus (Steindachner, 1868)'in otolit özellikleri ve bazı populasyon parametreleri, Journal of Fisheries Sciences, 6 (2), 114-124, (2012).

[20] Şahin, C., Kasapoğlu, N., Gözler, A.M., Kalaycı, F., Hacımurtazaoğlu, N., Mutlu, C., Age, growth, and gonadosomatic index (GSI) of Mediterranean horse mackerel (Trachurus mediterraneus Steindachner, 1868) in the Eastern Black Sea, Turkish Journal Zoology, 33, 157-167, (2009).

[21] Chugunova N.I., Age and growth studies in fish, National Science Foundation, Washington D.C., USA.133, (1963).

[22] Lagler, K.F., Freshwater fishery biology, W.M.C. Brown Company, Dubuque, IA. 421, (1966).

[23] Avşar, D., Balıkçılık Biyolojisi ve Populasyon Dinamiği, Çukurova Üniv., Ders Kitabı, Nobel yayıncilık Adana, 332, (2016).

[24] Sparre, P., Venama, S.C., Introduction to tropical fish stock assesment, Part I: Mannual, FAO Fish., Tech. L. Pap.Rev., 306-376, (1992).

[25] Karataş, M., Balık biyolojisi araştırma yöntemleri, Nobel Yayın, Ankara, 7186, (2005).

[26] Sümbüloğlu, K., Sümbüloğlu, V., Biyoistatistik, Hatipoğlu Yayınevi, 7. Bask1, Ankara, 269, (1997]

[27] Beverton, R.J., Holt, S.J., On the Dynamics of Exploited Fish Populations, Ministry of Agriculture, Fisheries and Food (Great Britain), Fishery Investigations, Series 2, 19 (1957).

[28] Viette, M., Giulianini, P.G., and Ferrero, E.A., Reproductive biology of scad, Trachurus mediterraneus (Teleostei, Carangidae), from the Gulf of Trieste, ICES Journal of Marine Science, 54: 267-272. (1997).

[29] Karakulak, F.S., Erk, H., Bilgin, B., Length-weight relationships for 47 coastal fish species from the northern Aegean Sea, Turkey, Journal of Applied Ichthyology, 22, 274-278, (2006).

[30] Petrakis, G, Stergiou, KI, Weightlength relationship for 33 species in Greek waters. Fisheries Research, 21, 465-469, (1995).

[31] Santic, Mç, Jardas, Iç, Pallaoro, A., Feeding habits of Mediterranean horse mackerel, Trachurus mediterraneus (Carangidae), in the Central Adriatic Sea. Cybium, 27 (4), 247-253, (2003).

[32] Yankova, M.H., Raykov, V.S., Gerdzhikov, D.B., Preteva, P.B., Growth and length-weight relationships of the horse mackerel, Trachurus mediterraneus ponticus (Aleev, 1956), off the Bulgarian Black Sea Coast. Turkish Journal of Zoology, 34, 85-92, (2010).

[33] Özdemir, S., Erdem, E., Aksu, H., Birinci Özdemir, Z., Determination of catch composition and length-weight relationship of some pelagic fishes caught by pairly midwater trawl, Journal of FisheriesSciences, 4(4), 427- 436 (2010). 
[34] Pešić, A., Joksimović, A., Đurović, M., Mandić, M., Marković, O., Ikica, Z., Biological characteristic of Mediterranean horse mackerel (Trachurus Mediterraneus, Steindachner, 1868) from the Montenegrin Shelf (Southern Adriatic), Water Research and Management, 2, 3 29-33, (2012).

[35] Demirel, N., Yüksek, A., Spawning Frequency of Trachurus mediterraneus (Carangidae) in the Sea of Marmara, Turkish Journal of Fisheries and Aquatic Sciences, 13: 441-446, (2013).

[36] Yankova, M., Population Dynamics of Horse Mackerel (Trachurus mediterraneus ponticus) in the Bulgarian Black Sea Coast. ISRN, Zoology Article ID 127287, 6, (2013a).

[37] Lucio, P., Biological aspects (growth and reproduction) of Mediterranean horse mackerel (Trachurus mediterraneus Steindachner 1868) in the Bay of Biscay. ICES CM 1996/H:19, 1-12. (1996).

[38] Prodonov, K., Mikhailov, K., Maxim, C., Chashchin, A., Arkhipov, A., Shlyakhov, V., Ozdamar, F., Environmental Management of Fish Resources in the Black Sea and their Rational Exploitation. General Fisheries Council for the Mediterranean, FAO Studies and Reviews, 60, 100-110, (1997).

[39] Raykov V., Yankova M., Growth dynamics and mortality estimation of the horse mackerel (Trachurus mediterraneus ponticus, Aleev) migrating along the Bulgarian Black Sea Coast for the period 2003 - 2005. Proceedings of first Biannual Scientific Conference "Black Sea Ecosystem and Beyond, BSK Istanbul, Turkey, 765-778, (2008)

[40] Dulcic, J., Kraljevic, M., Weight-length relationship for 40 species in the eastern Adriatic Sea (Croatian waters). Fisheries Research, 28, 243-251, (1996).

[41] Merella, P.A., Quetglas, Alemany, F., Carbonell, A.,. Length-weight relationship of fishes and cephalopods from the Balearic Islands (WesternbMediterranean)." Naga, ICLARM Q, 20 (3/4), 66-68, .(1997).

[42] Genç, Y., Zengin, M., Engin, S., Başar, I., Tabak, A., Ceylan, B., Investigation of economic seafoods, TKB. TAGEM/IY/96/17/3/01 project report, Institute of Fisheries, Trabzon, 156, (1999).

[43] Moutopoulos, D.K., Stergiou K.I., Length - weight and length - length relationships of fish species from the Aegean Sea (Greece). Journal of Applied Ichthyology, 18, 200-203, (2002).

[44] Yankova, M., Length-weight relationship of horse mackerel Trachurus mediterraneus Aleev, 1956 from Bulgarian Black Sea Coast, Journal of Black Sea/Mediterranean Environment, 20, 1, 18-24, (2014). 